\title{
Advancing Weaning Science: Shorter or Longer Duration of SBT? Illuminating the Road Ahead
}

Liberation of a patient from mechanical ventilation requires that the patient is capable of overcoming and sustaining the imposed work load. ${ }^{1}$ A spontaneous breathing trial (SBT) tests the ability of an individual patient to overcome the work of breathing experienced immediately after liberation from mechanical ventilation; SBTs presumably also predict the ability to sustain imposed work load over time. ${ }^{1}$ Implicit in the conduct of a SBT are 2 fundamental questions that a clinician considers: (1) Does the SBT successfully emulate conditions postextubation (capability)? (2) What is the duration of SBT that a patient must successfully tolerate prior to extubation (sustainability)? The combined goal of considering both questions is the minimization of extubation failure. Regardless of mechanism, extubation failure has consistently been shown to increase mortality and other adverse outcomes. ${ }^{2,3}$

In this issue of Respiratory CARE, Liang et $\mathrm{al}^{4}$ report on the latter question. Integrated statistical models using easily measurable clinical and physiological parameters predicted who would fail at 120 min with remarkable accuracy (receiver operating characteristic curve 0.88 before SBT and 0.98 at $30 \mathrm{~min}$ of SBT). Prior studies in large heterogeneous populations requiring invasive mechanical ventilation have found equivalence between 30-min and 120-min SBTs. ${ }^{5,6}$

A demographic score cut off of 2 identifies patients more likely to pass a 30-min SBT but fail at 120 minutes. Assessing physiologic metrics at 30 min for subjects who had scores of $>2$ by demographic criteria could improve clinician guidance in opting between 30-min and 120-min SBTs. Depending on the clinician's tolerance level for postextubation failure, a cut-off of $<2$ or $<3$ could be chosen for physiologic metrics. Alternatively, clinicians could rely on the demographic threshold alone and choosing a 120-min SBT for those with demographic scores $>2$. This would avoid need for physiologic and laboratory

\footnotetext{
The authors have disclosed no conflicts of interest.

Jonathon D Truwit MD MBA, Froedtert \& Medical College of Wisconsin, Froedtert Health Executive Office 4th Floor, Clinical Cancer Center Suite C4000 9200 West Wisconsin Avenue, Milwaukee, WI 53226 Email: Jonathon.truwit@froedtert.com or jtruwit@mcw.edu.
}

DOI: $10.4187 /$ respcare.06066 measurements 30 minutes into an SBT. However, of the $20 \%$ with demographic scores $>2$, a 30-min SBT would have been sufficient in $54 \%$.

\section{See the Original Study on Page 388}

The application of these results would apply only to patients undergoing a pressure-augmented SBT. As shown by Sklar et al, ${ }^{7}$ pressure agumentation both underestimates the work of breathing and the pressure-time product by $40-50 \%$. The former refers to a patient's capability to overcome the work load, and the latter refers to the sustainability of performing the work over time. Pressureaugmented SBTs may also cyclically unload the left ventricle and delay weaning-induced pulmonary edema, especially in patients with congestive heart failure.$^{8-10}$ It is plausible that if patients were weaned off all positive pressure (T-tubes or pressure support of 0 with PEEP of 0 ), weaning failure would be evident within $30 \mathrm{~min}$. To this point, cumulative fluid balance, volume status, dynamic hyperinflation, ejection fractions, diastolic function, and other markers of weaning-induced cardiac dysfunction would have been valuable in comparing groups. These are important confounders, especially in vulnerable patients such as those with chronic cardiopulmonary disease, which was present in $>70 \%$ of subjects in the failure group.

A vast majority of subjects in the cohort who failed SBT at $120 \mathrm{~min}$ had failed at least 1 prior SBT. Information regarding reasons for these prior failures and interventions undertaken to improve chances of subsequent SBT success were not provided. Failure of the first SBT is intuitively predictive of failure of subsequent SBTs if the cause for failure is either not reversed or only partially reversed. Failure of an SBT should trigger a search for imbalances between respiratory load and ability of the respiratory muscles to successfully sustain this load. ${ }^{11,12}$ Once this imbalance is fully corrected, a 30-min SBT might be adequate to discern success and failure.

Clinicians should also be aware that choosing a duration of SBT by way of a mathematical model that is based on the aggregation of several variables obscures the contribution of any single variable to a failed SBT and does not 


\section{EDITORIALS}

reveal the mechanism behind the failed SBT. Apart from identifying who requires a longer SBT, the clinician should also seek to understand the underlying cause of SBT failure to avoid cognitive bias. It is almost certain that if failure and success could reliably be differentiated, the majority of patients would desire a shorter rather than a longer SBT.

Lastly, it may be unwise to decide the duration of SBT based solely on a mathematical model and thus potentially delay extubation. It is not clear how many subjects who received 120 min of SBT would have failed extubation, as opposed to failing the SBT, had they been extubated after $30 \mathrm{~min}$, given that intensivists also have access to noninvasive ventilation, high-flow oxygen therapy, and skilled respiratory therapists to avoid re-intubation. ${ }^{13,14}$

As we weave the complex tapestry of weaning science, the study by Liang et $\mathrm{al}^{4}$ adds an important facet and illuminates the road ahead. It identifies a group of patients at high risk of extubation failure. It also suggests that a one-size-fits-all approach may be detrimental to a select cohort of patients. We must expeditiously identify these patients. Whether we accomplish this by performing SBTs for $120 \mathrm{~min}$ is still is matter of debate.

Rahul S Nanchal MD Jonathon D Truwit MD MBA Division of Pulmonary and Critical Care Medicine Froedtert Hospital Medical College of Wisconsin Milwaukee, Wisconsin

\section{REFERENCES}

1. MacIntyre NR, Cook DJ, Ely EW Jr., Epstein SK, Fink JB, Heffner JE, et al. Evidence-based guidelines for weaning and discontinuing ventilatory support: a collective task force facilitated by the American College of Chest Physicians; the American Association for Respir Care; and the American College of Crit Care Med Chest 2001; 120(6 Suppl):375S-395S.

2. Thille AW, Harrois A, Schortgen F, Brun-Buisson C, Brochard L. Outcomes of extubation failure in medical intensive care unit patients. Crit Care Med 2011;39(12):2612-2618.
3. Penuelas O, Frutos-Vivar F, Fernandez C, Anzueto A, Epstein SK, Apezteguia $\mathrm{C}$, et al. Characteristics and outcomes of ventilated patients according to time to liberation from mechanical ventilation. Am J Respir Crit Care Med 2011;184(4):430-437.

4. Liang G LT, Zeng Y, Shi Y, Yang W, Yang Y, Kang Y. Characteristics of patients who failed a 120-minute spontaneous breathing trial with $7 \mathrm{~cm} \mathrm{H2O}$ of pressure support. Respir Care 2018;388-394.

5. Perren A, Domenighetti G, Mauri S, Genini F, Vizzardi N. Protocoldirected weaning from mechanical ventilation: clinical outcome in patients randomized for a 30-min or 120-min trial with pressure support ventilation. Intensive Care Med 2002;28(8):1058-1063.

6. Esteban A, Alia I, Gordo F, Fernandez R, Solsona JF, Vallverdu I, et al. Extubation outcome after spontaneous breathing trials with T-tube or pressure support ventilation. The Spanish Lung Failure Collaborative Group. Am J Respir Crit Care Med 1997;156(2 Pt 1):459-465.

7. Sklar MC, Burns K, Rittayamai N, Lanys A, Rauseo M, Chen L, et al. Effort to breathe with various spontaneous breathing trial techniques. A physiological meta-analysis. Am J Respir Crit Care Med 2017;195(11):1477-1485.

8. Lamia B, Maizel J, Ochagavia A, Chemla D, Osman D, Richard C, et al. Echocardiographic diagnosis of pulmonary artery occlusion pressure elevation during weaning from mechanical ventilation. Crit Care Med 2009;37(5):1696-1701.

9. Lemaire F, Teboul JL, Cinotti L, Giotto G, Abrouk F, Steg G, et al. Acute left ventricular dysfunction during unsuccessful weaning from mechanical ventilation. Anesthesiology 1988;69(2):171-179.

10. Pinsky MR. Breathing as exercise: the cardiovascular response to weaning from mechanical ventilation. Intensive Care Med 2000; 26(9):1164-1166.

11. Cabello B, Thille AW, Roche-Campo F, Brochard L, Gomez FJ, Mancebo J. Physiological comparison of three spontaneous breathing trials in difficult-to-wean patients. Intensive Care Med 2010; 36(7):1171-1179.

12. Perren A, Brochard L. Managing the apparent and hidden difficulties of weaning from mechanical ventilation. Intensive Care Med 2013; 39(11):1885-1895.

13. Ferrer M, Valencia M, Nicolas JM, Bernadich O, Badia JR, Torres A. Early noninvasive ventilation averts extubation failure in patients at risk: a randomized trial. Am J Respir Crit Care Med 2006;173(2): 164-170.

14. Hernandez G, Vaquero C, Colinas L, Cuena R, Gonzalez P, Canabal A, et al. Effect of postextubation high-flow nasal cannula vs noninvasive ventilation on reintubation and postextubation respiratory failure in high-risk patients: a randomized clinical trial. JAMA 2016; 316(15):1565-1574. 